\title{
Efeito embriotóxico, teratogênico e abortivo de plantas medicinais
}

RODRIGUES, H.G. ${ }^{1 *}$; MEIRELES, C.G. ${ }^{2}$; LIMA, J.T.S. ${ }^{2}$; TOLEDO, G.P. ${ }^{2}$; CARDOSO, J.L. ${ }^{2}$; GOMES, S.L. ${ }^{2}$

${ }^{1}$ Ciências da Saúde (UNB), Faculdades Santo Agostinho de Montes Claros e Faculdades Integradas Pitágoras de Montes Claros (FIP-MOC), Avenida Professora Aída Mainartina Paraíso, 80, CEP: 39400-000, Ibituruna-Brasil *humbertobriel@yahoo.com.br ${ }^{2}$ Farmácia das Faculdades Integradas Pitágoras de Montes Claros (FIP-MOC), Avenida Professora Aída Mainartina Paraíso, 80, CEP: 39400-000, Ibituruna-Brasil

RESUMO: O uso milenar de plantas medicinais mostrou ao longo dos anos, que determinadas plantas apresentam substâncias potencialmente perigosas. Do ponto de vista científico, algumas pesquisas mostraram que muitas dessas plantas possuem substâncias agressivas e por essa razão devem ser utilizadas com cuidado, respeitando seus riscos toxicológicos. Os efeitos mais preocupantes do uso indiscriminado de plantas medicinais são embriotóxico, teratogênico e abortivo, uma vez, que os constituintes da planta podem atravessar a placenta, chegar ao feto e gerar um desses efeitos. Este estudo objetiva fornecer uma listagem das principais plantas medicinais que tenham efeitos embriotóxicos, teratogênicos e abortivos comprovados, conhecendo as partes da planta utilizadas e seus respectivos nomes científicos, com a finalidade de alertar gestantes quanto aos riscos de seu uso. Realizou-se buscas nas bases eletrônicas de dados SciELO, PubMed, MEDLINE, LILACS, CAPES e Google acadêmico. Nos resultados encontrados, plantas como Arnica (Arnica montana), Artemísia (Artemisia vulgaris), Arruda (Ruta chalepensis/ Ruta graveolens), Barbatimão (Stryphnodendron polyphyllum), Boldo (Vernonia condensata) dentre outras, podem vir a gerar um desses efeitos. A partir deste estudo comprova-se que para a maioria das plantas medicinais não há dados a respeito da segurança de seu uso durante a gravidez.

Palavras-chave: plantas medicinais, gestação, teratogênico, embriotóxico, abortivo

ABSTRACT: Embryotoxic, teratogenic and abortive effects of medicinal plants. The ancient use of medicinal plants has shown over the years that certain plants have potentially dangerous substances. From a scientific point of view, some studies have shown that many of these plants contain aggressive substances and therefore should be used with caution, respecting their toxicological risks. The most important effects of the indiscriminate use of medicinal plants are embryotoxic, teratogenic and abortifacient since the plant constituents can cross the placenta, reaching the fetus and leading to one of these effects. This study aimed to provide a list of the major medicinal plants that have proven embryotoxic, teratogenic and abortifacient effects, including the used plant parts and their respective scientific names, in order to warn pregnant women about the risks of its use. Searches were carried out in the electronic databases SciELO, PubMed, MEDLINE, LILACS, CAPES and Google Scholar. Results indicated that plants such as mountain arnica (Arnica montana), mugwort (Artemisia vulgaris), fringed rue (Ruta chalepensis / Ruta graveolens), "Barbatimão" (Stryphnodendron polyphyllum) and "Boldo" (Vernonia condensata) are likely to generate such an effect. This study shows that for most medicinal plants there are not data regarding the safety of their use during pregnancy.

Key words: medicinal plants, pregnancy, teratogenic, embryotoxic, abortifacient agents 


\section{INTRODUÇÃO}

A utilização de plantas com fins medicinais, para tratamento, cura e prevenção de doenças é uma das mais antigas formas de prática medicinal da humanidade (Veiga Júnior et al., 2005). No Brasil, essa prática é amplamente difundida e na maioria dos casos, a escolha de uma terapia baseada em plantas medicinais é sempre sem orientação médica. Um dos principais problemas da utilização destes produtos é a crença de que produtos de origem vegetal são isentos de reações adversas e efeitos tóxicos (Gallo \& Koren, 2001; Clarke, 2007). O uso milenar de plantas medicinais mostrou ao longo dos anos, que determinadas plantas apresentam substâncias potencialmente perigosas. Do ponto de vista científico, algumas pesquisas mostraram que muitas dessas plantas possuem substâncias agressivas e por essa razão devem ser utilizadas com cuidado, respeitando seus riscos toxicológicos (Veiga Júnior et al., 2005).

Os efeitos mais preocupantes do uso indiscriminado de plantas medicinais são teratogênico, embriotóxico e abortivo, uma vez que os constituintes da planta podem atravessar a placenta, chegar ao feto e gerar um desses efeitos (Brasil, 2002).

Para Embiruçui et al. (2005), os teratógenos constituem agentes ambientais, químicos, físicos e biológicos, que podem causar anormalidades obstétricas e (ou) fetais. Smithells (1980) define a teratologia como um termo que se refere ao ramo da ciência médica preocupado com o estudo da contribuição ambiental ao desenvolvimento pré-natal alterado.

A ação teratogênica sobre o embrião ou feto em desenvolvimento depende de diversos fatores, destacando-se o estágio de desenvolvimento do concepto, a elação entre dose e efeito, genótipo materno fetal e mecanismo patogênico específico de cada agente (Schüler-Faccini et al., 2002).

Acredita-se que a exposição à planta durante a gravidez seja somente responsável por cerca de $1 \%$ das malformações fetais. Embora essa porcentagem pareça pequena, os numerosos totais são expressivos. O estudo das ações das drogas sobre diversas fases do processo reprodutivo visa detectar os efeitos da fertilidade, transporte, embriogênese e organogênese, parto e recém-nascido. O risco teratológico existe durante todo período gestacional, no entanto é maior na fase de embriogênese, quando ocorrem à diferenciação tecidual e organogênese. É ainda possível que o desenvolvimento no período pós-natal possa sofrer alterações estruturais e metabólicas, a custa de substâncias utilizadas no período pré-natal (Araujo, 1998).

O efeito teratogênico da droga deve ser devido à potente ação uterotônica, promovendo um déficit transitório na circulação fetal que, a depender da intensidade do fenômeno vascular, do seu tempo de atuação e do momento de ocorrência, pode ocasionar um grande espectro de anomalias congênitas (Fonseca et al.,1991; Pastusazk et al., 1997). Apoiando este ponto de vista, Moreira et al. (2001) observam que vários fatores, tais como a absorção, metabolismo e distribuição maternos, transferência placentária e metabolismo fetal, interferem na suscetibilidade a um teratógeno potencial e são características únicas para cada par mãe/filho em função da heterogeneidade genética.

A embriotoxidade se refere à perturbação no desenvolvimento embrionário ou fetal, a custa de dosagens que não afetam o organismo materno. A embrioletalidade observada após administração de doses tóxicas para a mãe deve ser considerada como efeitos tóxicos gerais da planta. A reação do embrião aos agentes exógenos depende em grande parte da constituição genética do mesmo (Araujo, 1998).

O aborto é a interrupção da gravidez pela morte do embrião ou feto, junto com os anexos. Os médicos obstetras consideram o aborto até a 22a semana de desenvolvimento humano, após esse período, a interrupção da gravidez é considerada parto prematuro, e se houver óbito do feto, este é considerado natimorto. Sendo assim, até os cinco meses e meio de desenvolvimento humano, a eliminação do feto é considerada prática de aborto; dos cinco meses e meio em diante um parto prematuro. Mas a maioria dos abortos ocorre bem antes da 22a semana do desenvolvimento (Hardy et al., 1994).

O aborto é um método muito antigo de controle de natalidade, praticado em todas as civilizações. Embora seja reconhecido em diversos países, é proibido em quase toda a América Latina, o que não impede a prática no Brasil, com número próximo a meio milhão por ano, dos quais apenas $5 \%$ são permitidos pela lei (Farias et al.,1975). Entre os recursos abortifacientes mais comumente utilizados estão os chás e infusões de plantas medicinais. Existem também controvérsias sobre o efeito teratogênico das ervas medicinais, não apenas pela falta de comprovação científica, mas também pelas interações com outros remédios e a procedência dessas ervas (Moreira et al., 2001).

Dessa forma, o uso indiscriminado de plantas medicinais por gestantes é um problema de saúde pública, uma vez que as gestantes fazem o uso de plantas medicinais sem saber os possíveis efeitos causados por esse tipo de terapia. Vale destacar que, nesta revisão, o enfoque na clientela gestante justifica-se pelo fato de este período na vida da mulher exigir cuidados especiais, principalmente no primeiro trimestre de gestação. Diante da necessidade de se conhecer as plantas que poderiam causar efeitos embriotóxico, teratogênico ou abortivo, torna-se indispensável à realização dessa revisão que tem como objetivo levantar informações sobre plantas e

Rev. Bras. PI. Med., Botucatu, v.13, n.3, p.359-366, 2011. 
os possíveis efeitos teratogênicos, embriotóxicos e abortivo, que podem gerar riscos às gestantes.

As buscas foram realizadas nas bases eletrônicas de dados SciELO, PubMed, MEDLINE, LILACS, CAPES, Google acadêmico e Google. Este último se mostrou muito eficiente utilizando as palavras-chave (teratogênico, embriotóxico, abortivo, nome popular e científico da planta) com o termo "pdf" após a digitação das mesmas. Os critérios de inclusão eram artigos publicados recentemente; alguns artigos clássicos sem considerar a data de publicação; plantas selecionadas e que possuíam referências bibliográficas. Já os critérios de exclusão eram artigos que não abordavam as idéias principais a serem exposta no artigo; plantas que foram excluídas por não apresentar referências bibliográficas.

\section{Plantas medicinais com potencial embriotóxico, teratogênico e abortivo}

A utilização de espécies vegetais normalmente são para fins terapêuticos conhecidos a partir de ditos populares e que em alguns casos há comprovação científica. O que pouco se sabe é que essas mesmas plantas utilizadas para fins terapêuticos podem apresentar efeitos que são desconhecidos e que podem gerar transtornos para gestantes.

O uso dessas plantas pelas gestantes, deve seguir rigorosamente os mesmos cuidados dos medicamentos alopáticos, ou seja, sempre com o conhecimento médico prévio, já que, pôde-se observar em achados literários o fator embriotóxico, teratogênico e abortivo de muitas espécies.

A associação entre plantas e efeito teratogênico ou embriotóxico é escassa, entretanto, a relação entre plantas e efeito abortivo é mais freqüente. A Tabela 1 mostra a relação de 16 plantas com efeito abortivo; 7 plantas com efeito embriotóxico; 11 plantas com efeito teratogênico. O critério utilizado para organização da tabela foi ordem alfabética para o nome vulgar das plantas.

Dentre as plantas encontradas com efeitos comprovados, as partes comumente utilizadas são folhas, frutos, cascas dos galhos, flores e raízes variando de planta para planta e de acordo com sua constituição.

Os resultados encontrados para o "período a ser evitado" e a dosagem foram a partir de pesquisas realizadas em animas mais especificadamente, ratas Wistar, sendo que os períodos a serem evitados mais frequentes foram pré-implantação, pós-implantação e organogênese observados nesses animais. Já as doses que poderiam provocar o efeito, variaram de 0,500 a $7000 \mathrm{mg} \mathrm{kg}^{-1} \mathrm{dia}^{-1}$, além de depender da concentração que encontra-se a substância derivada da planta.

O período de pré-implantação compreende o período de 0-16 dias de gestação em humanos (Rang et al., 2004), na qual ocorre a diferenciação celular e conseqüente formação do blastocisto (Mello, 2000). A fase que antecede a implantação, fase préimplantação, representa um período de autonomia relativa do embrião. Nesta fase o embrião não depende apenas da circulação materna, mas necessita de secreções tubárias para sua manutenção e desenvolvimento e ainda de secreções autócrinas (O'neill, 1998). Na fase de pré-implantação, o embrião parece estar susceptível à letalidade do que a teratogenicidade. Durante essa fase, período entre a concepção e a implantação, o blastocisto parece ser muito sensível a ações de substâncias químicas, resultando em nenhum efeito ou morte do blastocisto (WHO, 1984). Mello (2000) afirma que o período de organogênese é o que compreende a formação definitiva dos órgãos, que ocorre normalmente no período de 17-60 dias de gestação em humanos. 0 período de pós-implantação ou período de histogênese e maturação funcional compreende o período após 60 dias de gestação em humanos (Rang et al., 2004).

Para Veiga Júnior et al. (2005), a angélica (Angelica archangelica), sucuúba (Himathantus sucuuba), alecrim (Rosmarinus officinales), arnica (Arnica montana), cânfora (Cinnamomum canphora), confrei (Symphytum officinale L.), eucalipto (Eucaliptus globulus) e sene (Cassia angustifolia e Cassia acutifolia) são abortivos, pois podem estimular a motilidade uterina e provocar aborto. A angélica é utilizada como anti-coagulante e a cânfora tem largo uso como anti-séptico e sedativo em problemas genitais e urinários; a sucuúba é usada no combate à amebíase, úlcera e gastrite. O alecrim apresenta propriedades estimulantes, antioxidantes, antiespasmódicas, anti-sépticas, antifúngicas e antibacterianas (Joly, 1993; Porte \& Godoy, 2001; Sartoratto et al., 2004; Adigüzel et al., 2005). A arnica é utilizada topicamente em contusões, entorces, hematomas, distensões musculares, flebites, artrites; o confrei é utilizado em úlceras de difícil cicatrização, psoríase, cicatrização de queimaduras, fissuras; o sene é utilizado como purgativa e laxativa (Londrina, 2006). O uso do Eucaliptus globulus (eucalipto) é especialmente eficaz no tratamento de inflamações pulmonares e mucosidade excessiva (Lavabre, 2001).

Estudos realizados com ratas wistar prenhas mostraram que arruda (Gonzales et al., 2006), barbatimão (Vitral et al., 1987), cambará (Mello et al., 2005), chapéu-de-couro (Toledo et al., 2004b), falso boldo (Almeida \& Lemonica, 2000), vidreira (Chan \& NG, 1995), Rhazya stricta (Rasheed et al., 1997) e Senecio latifolius (Steenkamp et al., 2001) apresentam efeitos que podem ser prejudicial a gestante e o concepto. A arruda (Ruta graveolens) possui atividade anti-helmíntica, anti-hemorrágica,

Rev. Bras. PI. Med., Botucatu, v.13, n.3, p.359-366, 2011. 
TABELA 1. Relação de plantas embriotóxicas, teratogênicas e abortivas comumente utilizadas pela população.

\begin{tabular}{|c|c|c|c|c|c|c|}
\hline $\begin{array}{l}\text { Nome } \\
\text { vulgar }\end{array}$ & Nome científico & Efeito & Parte usada & Dosagem & $\begin{array}{l}\text { Período a ser } \\
\text { evitado }\end{array}$ & Referências \\
\hline Alecrim & Rosmarinus officinalis & Abortivo & $\begin{array}{l}\text { Folhas e } \\
\text { gallos }\end{array}$ & - & - & $\begin{array}{l}\text { Joly, 1993; } \\
\text { Porte \& Godoy, 2001; } \\
\text { Sartorato et al., 2004; } \\
\text { Adiguzel et al., 2005 }\end{array}$ \\
\hline Angélica & Angelic a archangelica & Abortivo & Folhas & - & - & Veiga Junior et al. , 2005 \\
\hline Arnica & Amica montana & $\begin{array}{l}\text { Teratogênico } \\
\text { Abortivo }\end{array}$ & Folhas & - & - & $\begin{array}{l}\text { Londrina, 2006; } \\
\text { Veiga Junior et al. , } 2005\end{array}$ \\
\hline Arruda & $\begin{array}{l}\text { Ruta chalepensis / } \\
\text { Rutagraveolens }\end{array}$ & Embriotóxico & Folhas & $10 \mathrm{mg} \mathrm{kg}^{-1} \mathrm{dia}^{-1}$ & Pós-implantaçãd & $\begin{array}{l}\text { Matos, } 2000 ; \\
\text { Sousa et al., } 2004 ; \\
\text { Gonzales et al., } 2006\end{array}$ \\
\hline Artemísia & Artemísia vulgaris & $\begin{array}{l}\text { Teratogênico } \\
\text { Embriotóxico }\end{array}$ & Folhas & $6000 \underset{\mathrm{dia}^{-1}}{\mathrm{mg} \mathrm{kg}}$ & Organogênese & $\begin{array}{l}\text { Tigno et al., 2000; } \\
\text { Tigno \& Gumila, 2000; } \\
\text { Nacul et al., 2001; } \\
\text { Calliari, 1998; } \\
\text { Bortolini \& Martin, } 2001\end{array}$ \\
\hline Barbatimão & $\begin{array}{l}\text { Stryphno dendron } \\
\text { polyphyllum }\end{array}$ & Embriotóxico & Sementes & - & - & Vitral et al., 1987 \\
\hline Boldo & Vemonia condensata & Embriotóxico & Folhas & $\begin{array}{l}0,500 \text { a } 2000 \\
\mathrm{mg} \mathrm{kg}^{-1} \mathrm{dia}^{-1}\end{array}$ & - & Monteiro et al., 2001 \\
\hline $\begin{array}{l}\text { Boldo do } \\
\text { Chile }\end{array}$ & Peumus boldus & $\begin{array}{l}\text { Teratogênico } \\
\text { Abortivo }\end{array}$ & Folhas & - & - & $\begin{array}{l}\text { Newall et al., 1996; } \\
\text { Mengue et al., 2001; } \\
\text { Almeida et al., } 2000\end{array}$ \\
\hline $\begin{array}{c}\text { Bucha } \\
\text { Paulista ou } \\
\text { Cabacinha }\end{array}$ & Luffa operculata & $\begin{array}{c}\text { Abortivo } \\
\text { Embriotóxico }\end{array}$ & Frutos & - & - & $\begin{array}{l}\text { Mengue et al., 2001; } \\
\text { Schenkel et al., 2003; } \\
\text { Matos, 2000; } \\
\text { Sousa et al., } 2004\end{array}$ \\
\hline Cânfora & Cinnamomum canphora & Abortivo & Casca & - & - & Veiga Junior et al., 2005 \\
\hline Cambará & Lantana camara & Teratogênico & Folhas & $\begin{array}{l}3000 \text { a } 7000 \\
\mathrm{mg} \mathrm{kg}^{-1} \mathrm{dia}^{-1}\end{array}$ & $\begin{array}{l}\text { Pós- } \\
\text { implantação }\end{array}$ & $\begin{array}{l}\text { Seawrigth, 1965; } \\
\text { Shama et al., 1988; } \\
\text { Mello et al., } 2005\end{array}$ \\
\hline $\begin{array}{l}\text { Chapéu-de- } \\
\text { couro }\end{array}$ & Echinodorus macrophyllus & Abortivo & Folhas & $1 \mathrm{~mL} \mathrm{dia}{ }^{-1}$ & \begin{tabular}{|c|} 
Pré- \\
implantacão até \\
organogênese
\end{tabular} & Toledo et al., 2004b \\
\hline Confrei & Symphitum officinalis & Abortivo & Folhas & - & - & $\begin{array}{l}\text { Londrina, 2006; } \\
\text { Veiga Junior et al., } 2005\end{array}$ \\
\hline $\begin{array}{l}\text { Espinheira } \\
\text { Santa }\end{array}$ & Maytenus ilicifolia & Abortivo & Folhas & - & $\begin{array}{c}\text { Pré- } \\
\text { implantação }\end{array}$ & $\begin{array}{l}\text { Souza-Formig oni et al., } \\
1991 \text {; } \\
\text { Jorge et al., 2004; } \\
\text { Montanari \& Bevilacqua, } \\
2002\end{array}$ \\
\hline Eucalipto & Eucaliptus globulus & Abortivo & Folhas & - & - & $\begin{array}{l}\text { Veiga Junior et al., 2005; } \\
\text { Lavabre, } 2001\end{array}$ \\
\hline Falso Boldo & Coleus barbatus & $\begin{array}{c}\text { Teratogênico } \\
\text { Abortivo }\end{array}$ & Folhas & $880 \mathrm{mg} \mathrm{kg}^{-1} \mathrm{dia}^{-1}$ & Pré-mplantação & $\begin{array}{l}\text { Almeida \& Lemonica, } \\
2000\end{array}$ \\
\hline Gengibre & Zengiber officinale & Abortivo & Raiz & $1000 \underset{\mathrm{dia}^{-1}}{\mathrm{mg} \mathrm{kg}}$ & $\begin{array}{l}11 \text { semanas } \\
\text { gestacionais }\end{array}$ & Conover, 2003 \\
\hline $\begin{array}{l}\text { Ginseng } \\
\text { brasileiro }\end{array}$ & Pfaffia glomerata & Teratogênico & Raiz & $1 \mathrm{~mL} \mathrm{dia}{ }^{-1}$ & \begin{tabular}{|c|} 
Pré- \\
implantação até \\
organogênese
\end{tabular} & Toledo et al., 2004a \\
\hline Hortelã & Mentha piperita & Teratogênico & Folhas & - & - & $\begin{array}{l}\text { Vieira, 1992; Navarro, } \\
2000\end{array}$ \\
\hline $\begin{array}{l}\text { Ipê Roxo ou } \\
\text { Quina } \\
\text { Verdadeira }\end{array}$ & Tabebuia impetiginosa & $\begin{array}{l}\text { Teratogênico } \\
\text { Abortivo }\end{array}$ & Folhas & - & - & $\begin{array}{l}\text { Matos, 2002; Navarro, } \\
2000\end{array}$ \\
\hline
\end{tabular}


TABELA1. Relação de plantas embriotóxicas, teratogênicas e abortivas comumente utilizadas pela população.

... continuação

\begin{tabular}{|c|c|c|c|c|c|c|}
\hline $\begin{array}{l}\text { Nome } \\
\text { vulgar }\end{array}$ & Nome científico & Efeito & Parte usada & Dosagem & $\begin{array}{l}\text { Período a ser } \\
\text { evitado }\end{array}$ & Referências \\
\hline $\begin{array}{l}\text { Quebra } \\
\text { Pedra }\end{array}$ & Phyllanthus amarus & Abortivo & $\begin{array}{l}\text { Folhas, } \\
\text { flores e } \\
\text { frutos }\end{array}$ & - & - & $\begin{array}{l}\text { Matos, 2002; } \\
\text { Sousa et al., } 2004\end{array}$ \\
\hline Sene & $\begin{array}{l}\text { Cassia angustifolia / } \\
\text { Cas sia ac utifolia }\end{array}$ & Abortivo & Folhas & - & - & $\begin{array}{l}\text { Londrina, 2006; } \\
\text { Veiga Junior et al., 2005; }\end{array}$ \\
\hline Sucuúba & Himathantus sucuuba & Abortivo & Folhas & - & - & Veiga Junior et al., 2005; \\
\hline Vidreira & Tripterygium wilfordii & $\begin{array}{l}\text { Teratogênico } \\
\text { Embriotóxico }\end{array}$ & $\begin{array}{l}\text { Raízes } \\
\text { secas }\end{array}$ & $\begin{array}{l}50 \text { e } 100 \mathrm{mg} \\
\mathrm{kg}^{-1} \mathrm{dia}^{-1}\end{array}$ & Organogênese & $\begin{array}{l}\text { Zhang, 1992; Chan \& } \\
\text { NG, } 1995\end{array}$ \\
\hline- & Rhazy a stricta & $\begin{array}{l}\text { Embriotóxico } \\
\text { Teratogênico }\end{array}$ & Folhas & $\begin{array}{l}500 \text { a } 2000 \\
\mathrm{mg} \mathrm{kg}^{-1} \mathrm{dia}^{-1}\end{array}$ & $\begin{array}{c}\text { Pré- } \\
\text { implantação e } \\
\text { organogênese }\end{array}$ & $\begin{array}{l}\text { Rasheed et al.,1997; } \\
\text { Wasfi, } 1994\end{array}$ \\
\hline- & Senecio latifoliu & Teratogênico & $\begin{array}{l}\text { Caules e } \\
\text { follhas }\end{array}$ & $330 \mathrm{mg} \mathrm{dia}{ }^{-1}$ & - & Steenkamp et al. , 2001 \\
\hline
\end{tabular}

abortiva, carminativa, antiespamódica e estimulante. Indicada para reumatismo, hipertensão e verminoses. Contra indicada durante a gravidez, pois exerce fortes contrações no útero (Matos, 2000; Sousa et al., 2004). Além disso, estudos comprovaram o efeito embriotóxico e teratogênico a partir do extrato aquoso das folhas de Arruda (Ruta chalepensis) no período de pós-implantação (Gonzales et al., 2006). Já o Barbatimão (Stryphnodendron polyphyllum) apresenta atividade antioxidante e antimicrobiana (Soares et al., 2002). As sementes do barbatimão (Stryphnodendron polyphyllum) foram testadas em ratas grávidas na qual encontrou-se diminuição do peso dos ovários e do peso e medidas dos corpos lúteos gravídicos das ratas. A partir de então, acredita-se que o efeito do barbatimão ocorra através de alterações da zona basal da placenta, acarretando a morte embrionária e atrofia do corpo lúteo (Vitral et al., 1987).

Mello et al. (2005) afirmam que o cambará (Lantana camara) apresenta atividade embriotóxica. É utilizado para fins antipiréticos, antimicrobianos e antimutagênicos (Seawrigth, 1965; Sharma et al., 1988). A planta chapéu-de-couro (Echinodorus macrophyllus) é utilizada na medicina popular para tratamentos de doenças renais, reumatismo, afecções cutâneas e problemas do fígado. Em ensaios realizados com extratos aquosos de chapéude-couro em ratas, comprovou-se que os fetos apresentaram hepatomegalia branda, pontos hemorrágicos pelo corpo, pele viscosa. Um útero encontrava-se desprovido de fetos e preenchido com um líquido semelhante ao amniótico comprovando seu efeito abortivo (Toledo et al., 2004b). O efeito abortivo do falso boldo (Coleus barbatus) foi comprovado em estudo realizado no período de pré-implantação cujo efeito anti-implantação e desenvolvimento retardado
(Almeida \& Lemonica, 2000). O falso boldo é utilizado para o tratamento de problemas digestivos (Fischman et al., 1991).

Chan \& Ng (1995) afirmam que a vidreira (Tripterygium wilfordii) é embriotóxica. É potencialmente útil para doenças como lúpus eritematoso sistêmico ou síndrome nefrótica como afirma estudos farmacológicos utilizando animais (Zhang et al., 1992). Para Rasheed et al. (1997) a Rhazya stricta apresenta efeitos embriotóxicos ou teratogênicos, entretanto, a incidência de malformações como micromelia, hipoplasia maxilomandibular e edema, não fizeram alcance estatístico significativo, e ainda, a mesma é usada no tratamento de diabete mellitus, condições inflamatórias, helmintases e possui atividade microbiana. E o Senecio latifolius é uma planta usada no tratamento de queimaduras e ferimentos. Os alcalóides pirrolizidínicos presente nesta planta, pode estar relacionado ao efeito teratogênico provocado por esta planta (Steenkamp et al., 2001).

A atividade antiinflamatória é exercida tanto pela artemísia (Artemisia vulgaris) (Tigno et al., 2000) quanto pela espinheira santa (Maytenus ilicifolia) (Souza-Formigoni et al., 1991; Jorge et al., 2004). Além disso, a artemísia pode apresentar efeito antihipertensivo (Tigno et al., 2000; Tigno \& Gumila, 2000), digestivo, antiespasmódico, anti-helmíntico, reguladora da menstruação e provocar aborto (Nácul et al., 2001). Entretanto, quando as doses ingeridas são insuficientes para interromper a gestação, podem resultar em toxicidade para a gestante e o concepto (Calliari, 1998) ou em alterações no desempenho reprodutiva materna (Bortolini \& Martin, 2001). A espinheira santa (Maytenus ilicifolia) além de antiinflamtória, tem ação antiulcerogênica e 
antinoniceptiva (Souza-Formigoni et al., 1991; Jorge et al., 2004). Extratos hidroalcoólicos de espinheira santa mostraram-se abortivos por atuarem no período de pré-implantação dos embriões no útero (Montanari \& Belilacqua, 2002).

A plantas utilizadas para fins digestivos são boldo (Monteiro et al., 2001), boldo do Chile (Newall et al., 1996) e gengibre (Zingiber officinale). O extrato aquoso de folhas de boldo (Vernonia condensata) é indicado para tratamento da desordem gastrintestinal, enxaqueca, diarréia e além de possuir propriedades analgésicas. Possui baixa toxicidade e nenhuma evidência mostra risco de teratogenicidade ou mutagenicidade, entretanto o único efeito tóxico era um leve retardo de crescimento fetal ou embriotoxidade (Monteiro et al., 2001). O boldo do Chile (Peumus boldus) é indicado para hepatites, dispepsias hiposecretoras, mal estar, afecções do fígado e da vesícula, cálculo biliar, diarréia, digestão, febre, fraqueza orgânica, gota, insônia, má-flatulência, previne icterícia, prisão de ventre, problemas diuréticos, reumatismo, uréia (Newall et al., 1996). O Boldo do chile é teratogênico (Mengue et al., 2001) e estudos têm demonstrado ação abortiva e teratogênica (Almeida et al., 2000). Além atuar com auxílio digestivo, o gengibre (Zingiber officinale) é utilizado como estimulante, diurético e antiemético. Estudo realizado em ratos com 11 semanas de gestação obteve-se resultados terapêuticos que incluíam abortos, além disso, encontraram associação entre exposição pré-natal e aumento da perda fetal (Conover, 2003).

Segundo Navarro (2000), o ipê roxo (Tabebuia sp.) e hortelã (Mentha piperita) possuem efeito teratogênico. Foram encontrados ensaios-clínicos confirmando a atividade antineoplásica do Ipê Roxo (Matos, 2002). Já a hortelã é indicada para distúrbios gastrintestinais, vermífugo (giardíase e amebíase), gases, analgésica, anti-séptica, antiespasmódica, antiinflamatória, tônica, problemas respiratórios (Vieira, 1992). Quebra-pedra (Phyllanthus amarus) não pode ser utilizada durante a gravidez, pois possui princípios ativos que atravessam a barreira placentária, podendo provocar aborto, e essas substâncias também podem ser excretadas no leite materno (Matos, 2000; Souza et al., 2004). A quebrapedra (Phyllanthus amarus) possui propriedades diurética, hipoglicemiante, antiespasmódica, litolítica, colagoga (Londrina, 2006).

Muito comercializada para rinite e sinusite a bucha paulista ou cabacinha (Luffa operculata) (Mengue et al., 2001; Schenkel et al., 2003) possui substâncias denominadas cucurbitacinas responsáveis pelas ações embriotóxicas e abortivas, podendo causar hemorragia grave ou até mesmo a morte (Matos, 2000; Sousa et al., 2004). Ginseng (Pfaffia glomerata spreng) que é utilizado para fins afrodisíacos, calmante, contra úlcera e hipoglicemica. Em ensaios realizados com esta planta, foi possível observar malformações externas viscerais e esqueléticas, provocando mudanças estruturais que podem prejudicar o desenvolvimento dos fetos, observou-se também atraso no desenvolvimento fetal em relação a fetos controle (Toledo et al., 2004a).

\section{CONCLUSÃO}

Este estudo verificou que para a maioria das plantas medicinais não há dados a respeito da segurança de seu uso durante a gravidez. Os dados existentes são escassos e muitas vezes contraditórios. Dessa forma, a principal orientação para as mulheres grávidas é não utilizar qualquer medicamento, seja ele de origem vegetal ou não, sem o conhecimento prévio do seu médico, já que, pôdese observar em achados literários o fator embriotóxico, abortivo e teratogênico em algumas espécies. Outro dado que se comprova é que algumas plantas que apresentam efeito abortivo podem apresentar efeito embriotóxico ou teratogênico, isto é, se alguma planta vier a ser utilizada com finalidade de interrupção da gestação e esse fato não se consumar, a criança pode vir a nascer com problemas como malformação tanto de membros quanto de órgão e ou problemas relacionados a saúde.

Aos profissionais da área de saúde cabe informar às mulheres o risco da utilização de plantas medicinais e fitoterápicos durante a gravidez, chamando atenção para o perigo potencial da automedicação e das conseqüências associadas a ele. Se o emprego destes produtos se fizer necessário, que seja pelo menor período de tempo possível. Em todos os casos, é indispensável uma análise detalhada da situação da paciente e uma avaliação da relação risco-benefício para a futura mãe e feto.

\section{REFERÊNCIA}

ADIGÜZEL A. et al. Antimicrobial effects of Ocimum basilicum (Labiatae) extract. Turkish Journal of Biology, v.29, p.155-60, 2005.

ALMEIDA, F.C.G.; LEMONICA, I.P. The toxic effects of Coleus barbatus $B$. on the different periods of pregnancy in rats. Journal of Ethnopharmacology, v.73, p.53-60, 2000.

ALMEIDA, E.R.; MELO, A.M.; XAVIER, H. Toxicological evaluation of the hydro-alcohol extract of the dry leaves of Peumus boldus and boldina in rats. Phythoterapy Research, v.14, p.99-102, 2000.

ARAUJO, R.C. Estudo toxicológico das drogas. Correlação clinicopatologia. In: SILVA, P. Farmacologia. 5.ed. Rio de Janeiro: Guanabara Koogan, 1998. Cap.20, p.131-50.

BORTOLINI, C.E.; MARTIN, M.R.C. Performance reprodutiva de ratas tratadas com o extrato aquoso de

Rev. Bras. PI. Med., Botucatu, v.13, n.3, p.359-366, 2011. 
Artemísia vulgaris Linne, durante a gestação In: MOSTRA DE INICIAÇÃO CIENTíFICA, 11., 2001, Passo Fundo. Resumo... Passo Fundo: UPF, 2001. p.59.

BRASIL. Resolução SES no1757, de 18 de fevereiro de 2002. Contra-indica o uso de Plantas Medicinais no Âmbito do Estado do Rio de Janeiro e dá outras providências. Diário Oficial do Estado do Rio de Janeiro, 20 fev. 2002, v.27, n.33. Parte I.

CALLIARI, M.R.T. Effects of prenatal exposure to restraint stress and monocrotophos on behavioral and physical development in the rat. Genetics and Molecular Biology, v.21, n.3, p.171-178, 1998.

CHAN, W.Y.; NG, T.B. Adverse effect of Tripterygium wilfordii extract on mouse embryonic development. Contraception, v.51, p.65-71, 1995.

CLARKE, J.H.R.; RATES, S.M.K.; BRIDI, R. Um alerta sobre o uso de produtos de origem vegetal na gravidez. Infarma, v.19, n.1/2, p.41-8, 2007.

CONOVER, E.A. Herbal agents and over-the-counter medications in pregnancy. Best Practice \& Research Clinical Endocrinology and Metabolism, v.17, n.2, p.23751, 2003.

EMBIRUÇUI, E.K. et al. Risco teratogênico: a percepção em diferentes segmentos da população. Revista de Ciências Médicas e Biológicas, v.4, n.3, p.201-7, 2005. FARIAS, F.; SATURNINO, J.; NASCIMENTO, N. Aborto provocado: condições sócio-econômicas e culturais. Programa de Reprodução Humana. Salvador: Universidade Federal da Bahia, 1975. 102p.

FISCHMAN, L.A. et al. The water e extract of Coleus barbatus Benth. decrease gastric secretion in rats. Memórias do Instituto Oswaldo Cruz, v.86, n.2, p.1413,1991.

FONSECA, W. et al. Misoprostol and congenital malformations. The Lancet, v.338, n.2, p.56, 1991.

GALLO, M.; KOREN, G. Can herbal products be used safely during pregnancy? Focus on Echinacea. Canadian Family Physician, v.47, p.1727-8, 2001.

GONZALES, J.R. et al. Efecto embriotóxico y teratogénico de Ruta chalepensis L. «ruda», en ratón (Mus musculus). Revista Peruana Biologia, v.13, n.3, p.223-5, 2006.

HARDY, E. et al. Características atuais associadas à história de aborto provocado. Revista Saúde Pública, v.28, n.1, p.82-5, 1994.

JOLY, A.B. Botânica: introdução à taxonomia vegetal. 11.ed. São Paulo: Companhia Editora Nacional, 1993. $777 p$.

JORGE, R.M. et al. Evaluation of antinociceptive, antiinflammatoryand antiulcerogenic activities of Maytenus ilicifolia. Journal Ethnopharmacology, v.94, n.1, p.93-100, 2004.

LAVABRE, M. Aromaterapia: a cura pelos óleos essenciais. 5.ed. Rio de Janeiro: Record Editora Nova Era, 2001. p.18-89.

LONDRINA. Prefeitura do Município. Autarquia Municipal de Saúde. Fitoterapia: protocolo. Londrina, 2006.

MATOS, F.J.A. Plantas medicinais: guia de seleção e emprego de plantas usadas em fitoterapia no nordeste do Brasil. 2.ed. Fortaleza: Editora UFC, 2000. 344p.

MATOS, F.J.A. Farmácias vivas: sistema de utilização de plantas medicinais "projeto para pequenas comunidades". Fortaleza: EUFC, 2002. 267p.

MELLO, F.B. et al. Effects of Lantana camara
(Verbenaceae) on general reproductive performance and teratology in rats. Toxicon, v.45, p.459-66, 2005.

MELLO, R.A. Embriologia humana. São Paulo: Editora Atheneu, 2000. p.37-97.

MENGUE, S.S.; MENTZ, L.A.; SHENKEL, E.P. Uso de plantas medicinais na gravidez. Revista Brasileira Farmacognosia, v.11, p.21-35, 2001.

MONTANARI, T.; BEVILACQUA, E. Effect of Maytenus ilicifolia Mart. on pregnant mice. Contraception, v.65, n.2, p.171-5, 2002.

MONTEIRO, M.H.D. et al. Toxicological evaluation of a tea from leaves of Vernonia condensata. Journal of Ethnopharmacology, v.74, n.2, p.149-57, 2001.

MOREIRA, L.M.A. et al. Associação entre o uso de abortifacientes e defeitos congênitos. Revista Brasileira de Ginecologia e Obstetrícia, v.23, n.8, p.517-21, 2001. NÁCUL,A.P.; CALLIARI-MARTIN, M.R.; CECHETTI, D. Uso de plantas medicinais com finalidade abortiva na periferia de Passo Fundo. In: MOSTRA DE INICIAÇÃO CIENTÍFICA DA UPF, 11., 2001, Passo Fundo. Resumo... Passo Fundo: UPF, 2001. p.55.

NAVARRO, M.C.M. Uso racional de las plantas medicinales. Pharmaceutical Care Espana, v.2, p.9-19, 2000.

NEWALL, C.A.; ANDERSON L.A.; PHILLIPSON, J.D. Herbal medicines: a guide for healthcare professionals. London: Pharmaceutical Press, 1996. p.145-50.

O'NEILL, C. Autocrine mediators are required to act on the embryo by the 2-cell stage to promote normal development and sulvival of mouse preimplantecion embryos in vitro. Biology and Reproduction, v.58, p.13039,1998.

PASTUSAZK, A.L. et al. Misoprostol use during pregnancy is associated with increased risk for Mobius sequence. In: MEETING OF THE TERATOLOGY SOCIETY, Londres, 1997. Teratology - The Journal of Abnormal Development. New York : Wiley-Liss, 1997. p.36.

PORTE, A.; GODOY, R.L.O. Alecrim (Rosmarinus officinalis L.): propriedades antimicrobiana e química do óleo essencial. Boletim Centro de Pesquisa de Processamento de Alimentos, v.19, n.2, p.193-210, 2001.

RANG, H.P. et al. Efeitos nocivos dos fármacos. In: RANG, H.P. et al. Farmacologia. 5.ed. Rio de Janeiro: Editora Elsevier, 2004. p.825-56.

RASHEED, A.R. et al. Effect of Rhazya strzcta on the developing rat fetus. Reproductive Toxicology, v.11, n.2, p.191-9, 1997.

SARTORATTO, A. et al. Composition and antimicrobial activity of essential oils from aromatic plants used in Brazil. Brazilian Journal of Microbiology, v.35, n.4, p.27580, 2004.

SCHÜLER-FACCINI, L. et al. Avaliação dos teratógenos na população brasileira. Ciência \& Saúde Coletiva, v.7, n.1, p.65-71, 2002.

SEAWRIGTH, A.A. Toxicity for the Guinea pig of an extract of Lantana camara. Journal of Comparative Pathology, v.75, p.215-21, 1965.

SHARMA, O.P.; MAKKAR, H.P.S.; DAWRA, R.K. A review of the noxious plant Lantana camara.Toxicon, v.26, n.11, p.975-87, 1988.

SCHENKEL, E.P. et al. Plantas tóxicas. IN: SIMÕES, C.M.O. et al. Farmacognosia: da planta ao medicamento.

Rev. Bras. PI. Med., Botucatu, v.13, n.3, p.359-366, 2011. 
5.ed. Porto Alegre/Florianópolis: Editora da UFRS/UFSC, 2003. p.959-93.

SMITHELLS, R.W. The challenges of teratology. Teratolology, v.22, p.77-85, 1980.

SOARES, J.DH. et al. Atividade tripanocida in vivo de Stryphnodendron adstringens (barbatimão) e Caryocar brasiliensis (pequi). Revista Brasileira de Farmacognosia, v.12, p.1-2, 2002.

SOUSA, M.P. et al. Constituintes químicos ativos e propriedades biológicas de plantas medicinais brasileiras. 2.ed. Fortaleza: Editora UFC, 2004. 448p.

SOUZA-FORMIGONI, M.I.O. et al. Antiulcerogenic effects of two Maytenus species in laboratory animals. Revista Brasileira de Famacognosia, v.34, p.21-7, 1991.

STEENKAMP, V. et al. The effect of Senecio latifolius a plant used as a South African traditional medicine, on a human hepatoma cell line. Journal of Ethnopharmacology, v.78, n.1, p.51-8, 2001.

TIGNO, X.T.; GUMILA, E. In vivo microvascular actions of Artemisia vulgaris $\mathrm{L}$. in a model of ischemia-reperfusion injury in the rat intestinal mesentery. Clinical Hemorheology and Microcirculation, v.23, n.2/4, p.159-65, 2000.

TIGNO, X.T.; DE GUZMAN, F.; FLORA, A.M. Phytochemical analysis and hemodynamic actions of Artemisia vulgaris L. Clinical Hemorheology and Microcirculation, v.23, p.167-75, 2000.

TOLEDO, M.R.S. et al. Extratos aquosos de Pfaffia glomerata $S$. e seu efeito tóxico em ratas prenhes, Revista Horticultura Brasileira, v.22, n.2, p.493, 2004a. TOLEDO, M.S. et al. Comparação da Fitotoxicidade dos extratos aquosos de Echinodorus macrophyllus (Kunt) Mich. em ratas prenhes. Revista Horticultura Brasileira, v.22, n.2, p.493, 2004b.

VEIGA JÚNIOR, V.F.; PINTO, A.C.; MACIEL, M.A.M. Plantas medicinais: cura segura? Química Nova, v.28, n.3, p.51928, 2005.

VIEIRA, L.S. Fitoterapia da Amazônia: manual de plantas medicinais (a Farmácia de Deus). 2.ed. São Paulo: Editora Agronômica Ceres, 1992. 347p.

VITRAL, G.S.F.; PETERS, V.M.; GUERRA, M.O. Mecanismos da ação embriótoxica do barbatimão (Stryphnodendron polyphyllum M.). Reprodução \& Climatério, v.3, p.222-6, 1987.

WASFÍ, L.A. The effect of Rhazya stricta on glucose homeostasis in normal and streptozototin diabetic rats. Journal of Ethnopharmacology, v.43, p.141-7,1994.

WORLD HEALTH ORGANIZATION - WHO. Principles for evaluating health risks to progeny associated with exposure to cheminicals during pregnancy. Geneva: WHO, 1984.

ZHANG, X.Y. et al. Prolonged survival of MRL-lpr/lpr mice treated with Tripterygium wilfordii Hook F. Clinical Immunology and Immunopathology, v.62, n.1, p.6671,1992 . 